\title{
"Es música el silencio". Suspensión de la palabra y poética de lo sagrado en Octavio Paz
}

\section{"Silence is music". \\ Suspension of the word and poetics of the sacred in Octavio Paz}

\author{
Paul-Henri Giraud \\ Université de Lille, France ${ }^{1}$ \\ paul-henri.giraud@univ-lille.fr
}

Resumen: Muchas veces, en Paz, el proceso poético mismo y la experiencia de plenitud a la que lleva se dejan describir en términos cuasi religiosos, como un camino de iniciación que desemboca en una especie de éxtasis. El presente artículo se propone indagar las relaciones entre la palabra poética y lo sagrado en la obra del poeta mexicano, ciñéndose, más particularmente, a la noción de silencio. Es en los años de su más larga estadía en la India, como embajador de México, entre I962 y I968, cuando Paz tematiza el silencio como "culminación" de la palabra, confiriéndole un aura sagrada. Pero se pueden encontrar ecos de tal concepción en la etapa final de su escritura, y hasta en su último poema.

Palabras claves: palabra, silencio, sagrado, Buda, otredad.

${ }^{1}$ Univ. Lille, ulr 4074 -CECILLE- Centre d'Études en Civilisations Langues et Lettres Étrangères, F-59000 Lille, France. 
Abstract: Often, in Paz, the poetic process itself and the experience of fullness to which it leads are described in quasi-religious terms, as a path of initiation that leads to a kind of ecstasy. This article aims to investigate the relationship between the poetic word and the sacred in the work of the Mexican poet, adhering more particularly to the notion of silence. It was during the years of his longest stay in India, as ambassador of Mexico, between I962 and 1968, that Paz made silence the "culmination" of the word, giving it a sacred aura. But echoes of such a conception can be found in the final stage of his writing, and even in his last poem.

Keywords: Word, Silence, Sacred, Buddha, Otherness.

Recibido: 30 de enero de $202 \mathrm{I}$

Aceptado: 27 de abril de $202 \mathrm{I}$ https://dx.doi.org/I O.I 5 I 74/rv.vi 3i28.604

Silences traversés des Mondes et des Anges

Arthur Rimbaud

Zn un texto de 1966, no ensayístico sino aforístico, Octavio EPaz da una formulación muy nítida de su concepción de la relación entre palabra y silencio:

La palabra se apoya en un silencio anterior al habla -un presentimiento de lenguaje. El silencio, después de la palabra, reposa en un lenguaje -es un silencio cifrado. El poema es el tránsito entre uno y otro silencio -entre el querer decir y el callar que funde querer y decir (Recapitulaciones, oc11: 297). 
Según esta concepción, la palabra poética se sitúa entre dos posos de silencio. Entre un atisbo y un gusto. Entre un "presentimiento" y un "querer". Proferirla, oírla o leerla corresponden un proceso a la vez intermedio y mediador: el de hacernos pasar de una actitud de escucha o espera a otro tipo de silencio, "cifrado", hecho de fruición y misterio.

Muchas veces, en Paz, el proceso poético mismo y la experiencia de plenitud a la que lleva se dejan describir en términos cuasi religiosos, como un camino de iniciación que desemboca en una especie de éxtasis. El presente artículo se propone indagar las relaciones entre la palabra poética y lo sagrado en la obra del poeta mexicano, retomando algunas consideraciones anteriores (Giraud, 2014) y ciñéndose, más particularmente, a la noción de silencio. Es en los años de su más larga estadía en la India, como embajador de México, entre 1962 y 1968, cuando Paz tematiza el silencio como "culminación" de la palabra, confiriéndole un aura sagrada. Pero se pueden encontrar ecos de tal concepción en la etapa final de su escritura, y hasta en su último poema.

\section{Lo sagrado, mediación y ámbito}

Según el filósofo español Juan Martín Velasco, el concepto de lo sagrado "puede ser utilizado en dos sentidos: como ámbito de realidad que surge en la vida humana cuando el hombre vive su referencia al Misterio, y como conjunto de mediaciones concretas a través de las cuales el hombre reconoce y vive la aparición del misterio" (Martín Velasco, 1993: 323). La primera acepción de la palabra sagrado -la de un ámbito de realidad particular que emerge cuando el hombre experimenta su vínculo con el Misterio-, se aviene con lo que Max Scheler denominaba "esfera del ser" [Seinssphäre] (Martín Velasco, 1993: 88; nota 3) y lo que Octavio Paz, en El arco y la lira (1956), llama "el universo", "la zona”, "la 
esfera", "la atmósfera" o, incluso -en una metáfora de resonancias surrealistas- "la zona eléctrica" 2 de lo sagrado. La segunda acepción -la de un conjunto de mediaciones concretas- se puede aplicar al proceso mismo de la palabra poética, que Paz evoca como una suerte de procesión auditiva, visual y mental: "Las palabras entran por el oído, aparecen ante los ojos, desaparecen en la contemplación. Toda lectura de un poema tiende a provocar el silencio" (Recapitulaciones, OC11: 294).

A continuación, distinguiremos en este proceso varios aspectos. A la inminencia de la palabra en el silencio inicial corresponde, después de la palabra, una "música" propia del silencio. El proceso poético introduce entonces a la experiencia de la otredad, que el budismo llama "la otra orilla". Por último, una fundamental actitud de escucha propicia una "procesión" 3 de palabras que a veces se traduce, simbólicamente, en un caminar -en una "peregrinación hacia las claridades"-(Blanco, OC11: 437).

"El silencio es música"

Anoche un fresno

a punto de decirme

algo —callóse.

Haiku perfecto desde el punto de vista de la métrica (5/7/5 sílabas), este micro-poema titulado "Prójimo lejano" (OC11: 379) y sacado de Ladera este $e^{4}$ corresponde a la estética japonesa de lo

${ }^{2}$ Véase, respectivamente, OC1 (134; 134; 138; 278, y 131). Y también otras expresiones aplicadas a la poesía: "zona armónica" (OC1: 75), "ámbito eléctrico" (OC1: 195).

${ }^{3}$ Octavio Paz, "Advertencia", Blanco (OC11: 422).

${ }^{4}$ Publicado en 1969, este libro recoge los poemas escritos por Paz en Oriente entre 1962 y 1968. 
inconcluso: "la sensación de que un poema está siempre a punto de terminar, sin llegar nunca -como lo pretende el arte occidental- a terminar por completo" (Weinberger, 1990: 106). La gracia de este texto consiste en un decir que culmina en un callar, y al mismo tiempo en un susurro: "callóse". El fresno evocado se yergue en la soledad cual emblema metapoético: el propio poema se calla al mismo tiempo que el fresno.

En "Los signos en rotación" (1965), ensayo escrito por Paz en esos mismos años, encontramos una situación o parábola parecida. Aquí Paz asimila el descubrimiento de un árbol en el paisaje -percepción visual y auditiva a la vez- a una revelación un tanto onírica, cuyo sentido ha sido pre-sentido y luego olvidado. Queda la imagen del "árbol aquel" y una intensa aprensión del "Ser", manifestado en el tiempo, glorificado en el Estar:

[...] la tarde en que vimos el árbol aquel en medio del campo y adivinamos, aunque ya no lo recordemos, qué decían las hojas, la vibración del cielo, la reverberación del muro blanco golpeado por la luz última [...]. Solos o acompańados hemos visto al Ser y el Ser nos ha visto. ¿Es la otra vida? Es la verdadera vida, la vida de todos los días (OC1: 260).

Ver al Ser implicaría, pues, ser visto por Él, es decir por "lo Otro".5 "La verdadera vida" es experimentar la otredad al ser alcanzado por ella. El árbol bien plantado en este breve pasaje de poesía en prosa resulta ser, de nuevo, un símbolo del texto poético, el cual no deja de permanecer, como el árbol, a la vez promisorio y enigmático: "Plantado sobre lo informe $[\ldots]$ y $[\ldots]$ en busca de

${ }^{5}$ Paz retoma esta expresión de Rudolf Otto. En alemán, das Ganzandere significa, literalmente, lo absolutamente Otro (Otto, 1980: 41), conforme a la traducción española citada en El arco y la lira (OC1: 141). 
un significado sin cesar elusivo, el poema es un espacio vacío pero cargado de inminencia" (OC1: 247).

Celosos de su sentido, esquivos en su vaivén danzante por el blanco de la página, los poemas de Ladera este llaman la atención del lector por sus versos escalonados. Esos versos furtivos nos miran y se van; nos interrogan y burlan nuestras interpretaciones por una mezcla peculiar de plenos y vacíos, de silencio y de música: "los espacios en blanco (que representan al silencio, y tal vez por eso mismo), dicen algo que no dicen los signos. La escritura proyecta una totalidad pero se apoya en una carencia: no es música ni es silencio y se alimenta de ambos", dice Paz (OC1: 270).

El poema "Lectura de John Cage" desarrolla esta paradoja (OC11:380):

\footnotetext{
La música

inventa al silencio,

la arquitectura

inventa al espacio.
}

En estos versos, el fenómeno mismo pareciera crear su más allá. La arquitectura "inventa" su ausencia: "el espacio" que la rodea cobra sentido y descubre su orden propio gracias a la arquitectura. La música "inventa" su abolición, que es tal vez su más alta creación: el silencio. Gracias a la música, el tiempo se abre en un instante vivaz y nos deja entrever la posibilidad de liberarnos del tiempo. De un verso a otro, el tránsito del lector a través de los contrarios lo lleva a trascenderlos en una realidad superior, inefable, que se susurra en un oxímoron (OC11: 382):

el sol es nieve,

el silencio es música.

(The situation must be Yes-and-No, 
not either-or)

Puesta entre paréntesis y transcrita en inglés, la sentencia de John Cage ${ }^{6}$ asigna a la música, y a todo arte, el fin místico de la coincidentia oppositorum -la "coincidencia de los opuestos" en un "tercer estado", como lo puntualiza el poema Pasado en claro ([1975]-OC12: 89):

hay un tercer estado.

Hay un estar tercero:

el ser sin ser, la plenitud vacía [...]

Este estado paradójico caracteriza la otredad, que Paz describe como un "don". Es propiamente una gracia que, en esta vida, instaura otra vida:

Es un don imprevisto, un signo que la vida hace a la vida sin que el recibirlo entrañe mérito o diferencia alguna, ya sea de orden moral o espiritual. [...] Experiencia hecha del tejido de nuestros actos diarios, la otredad es ante todo percepción simultánea de que somos otros sin dejar de ser lo que somos y que, sin cesar de estar donde estamos, nuestro verdadero ser está en otra parte. Somos otra parte ("Los signos en rotación", OC1: 258).

Pero ¿dónde estamos cuando somos otros? Estamos "en la otra orilla”.

${ }^{6}$ Una nota de Octavio Paz remite a dos libros de Cage: Silence (1961) y A Year from Monday (1967). "Las frases en inglés y subrayadas pertenecen al segundo" (OC11 549). 


\section{"La otra orilla"}

Título de uno de los capítulos de El arco y la lira, "La otra orilla" estuvo a punto de ser el del propio libro. ${ }^{7}$ Este capítulo cita un texto antiquísimo encontrado por Paz en un estudio sobre el budismo zen (OC1: 135):

Hui-neng, patriarca chino del siglo vII, explica así la experiencia central del budismo: "Mahaprajnaparamita es un término sánscrito del país occidental; en lengua Tang significa: gran-sabiduríaotra-orilla-alcanzada... ¿Qué es Maha? Maha es grande... ¿Qué es Prajna? Prajna es sabiduría... ¿Qué es Paramita?: la otra orilla alcanzada... Adherirse al mundo objetivo es adherirse al ciclo del vivir y el morir, que es como las olas que se levantan en el mar; a esto se llama: esta orilla... Al desprendernos del mundo objetivo, no hay ni muerte ni vida y se es como el agua corriendo incesante; a esto se llama: la otra orilla". ${ }^{8}$

Esta orilla simboliza el mundo profano: el del devenir y la caducidad, la fatal alternancia de los contrarios, la dualidad perpetua. En la otra orilla -el ámbito de lo sagrado-, toda oposición ha sido trascendida, sublimada. El espacio y el tiempo profanos quedan abolidos: "aquí es allá"; "ayer es hoy" (OC1: 139). El principio lógico y ontológico de no contradicción cede ante la fusión universal de los contrarios. Sabrosa sabiduría que Paz quiso desentrañar en aforismos, ensayos y en poemas a lo largo de los años sesenta:

${ }^{7}$ Cfr. la carta de Octavio Paz a Alfonso Reyes del 25 de julio de 1953 (Stanton, 1998: 208).

${ }^{8}$ Suzuki (1950 apud. OC1: 135; nota 1). En la edición de las Obras Completas, Paz señala en una nota la traducción habitual de Paramita: la perfección. No es menos cierto que el sentido literal de esta palabra es "lo que alcanzó la otra orilla" (Dictionnaire de la sagesse orientale: 423 ). 
Lo que nos propone el budismo es el fin de las relaciones, la abolición de las dialécticas - un silencio que no es la disolución sino la resolución del lenguaje (Recapitulaciones, OC11: 296).

El silencio del Buda no es un conocimiento sino lo que está después del conocimiento: una sabiduría (Claude Lévi-Strauss o el nuevo festín de Esopo [1967], OC10: 557).

Ladera este culmina en su último texto, el más extenso, Blanco. La "Advertencia" preliminar de este poema complejo, compuesto de varias columnas y colores - de varios poemas en realidad-, lo describe así: "la columna del centro, con exclusión de las de izquierda y derecha, es un poema cuyo tema es el tránsito de la palabra, del silencio al silencio (de lo 'en blanco' a lo blanco -al blanco-)" (OC11: 422). Así pues, el "blanco" último -la iluminación, la "vacuidad... vacía de su vacuidad"-9 es el "blanco" -el objeto y la meta del poema-. El desenvolvimiento del poema lo transforma en un mandala, soporte visual de meditación y de iniciación, que nos lleva del silencio al silencio -del blanco al blanco-:

La puerta de entrada es el breve poema inicial sobre la palabra: pero es la palabra antes de ser dicha, el silencio antes de la palabra, la palabra en blanco. [...] La puerta de salida, es decir, la [...] parte [...] final, corresponde al espacio blanco, en el que se han fundido todos los colores, el horizonte, lo que está más allá. Y alude también al silencio después de la palabra. ${ }^{10}$

${ }^{9}$ Octavio Paz, nota al poema "Maithuna" (OC11: 551).

${ }^{10} \mathrm{Vid}$. "Cuarenta años de escribir poesía, V", fragmento de una conferencia dictada en El Colegio Nacional de México [1975] (Archivo Blanco: 120-121). 
Para ilustrar esta descripción, se podrían citar muchos versos de Blanco. A título de muestra, en el fragmento siguiente, un neologismo se prolonga en metáforas y comparaciones donde la luz y la transparencia se asocian a enigmáticas "verdades", equivalentes al sublime "silencio" (OC11 [437-438]):

Aerofanía,

boca de verdades,

claridad que se anula en una sílaba

diáfana como el silencio: $[\ldots]$

Al final del poema, tanto la realidad como el texto mismo -"esta música" (OC11 [443]) - se resuelven en un solo "sonido" (en sánscrito: nada). En la Nada-Bindu (la "vibración original") que coincide, en español, con la palabra nada (Weinberger, 1994: 198-199). En la música misma del silencio (OC11 [445-446]):

\section{Silencio}

sello

centelleo

en la frente

en los labios

antes de evaporarse

Como las llamas de un fuego sutil ardiendo en pleno día, las palabras cursivas revolotean por el blanco de la página, "hasta el vacío esencial, hasta la pura desaparición vibratoria" (Esteban, 1987: 219). 


\section{Escucha, peregrinación, desprendimiento}

Nunca como en la India, ese escritor tan visual como fue Paz insistió tanto sobre la necesidad para el poeta de escuchar. La misma configuración plástica de las palabras sobre la página se concibe como una invitación a la audición:

[...] el poeta escucha. En el pasado fue un hombre de la visión. Hoy aguza el oído y percibe que el silencio mismo es voz, murmullo que busca la palabra de su encarnación. El poeta escucha lo que dice el tiempo, aun si dice: nada. Sobre la página unas cuantas palabras se reúnen o desgranan. Esa configuración es una prefiguración: inminencia de presencia ("Los signos en rotación", OC1: 270).

Años después, en Árbol adentro (1987), se interioriza el poema paciano. Pierde algo de su brillo enceguecedor. Une texto breve, titulado "No-visión", empieza evocando la penumbra del pensamiento y sugiere el eco hueco de una cisterna. Sensación inmediata donde el yo se embebe, olvidadizo, desindividualizado, y se abre a un renacer (OC12: 102):

Hora nula, cisterna

donde mi pensamiento

a sí mismo se bebe.

Por un instante inmenso

he olvidado mi nombre.

Poco a poco desnazco, diáfano advenimiento. 
Desaparecidos los nombres, "desnacido" el hombre, calla el poema, pero calla en la luz. Como al final de Blanco, "la transparencia es todo lo que queda" (OC11: 432).

"El silencio", según Paz, "no es el fracaso sino el acabamiento, la culminación del lenguaje" (Conjunciones y disyunciones [1969], OC10: 120). La poesía -como el erotismo, igual que la pintura tántrica y el arte en general- no es un fin en sí misma sino un camino hacia un allá inubicable -"una peregrinación que se resuelve en un desprendimiento" ("El pensamiento en blanco", OC6: 62)-. En este mismo ensayo que acabamos de citar -"prefacio a la primera exposición de arte tántrico en Occidente, Galería Le Point Cardinal, París, febrero de 1970"-, se desarrolla la metáfora del caminar:

Escribir o leer es trazar o descifrar signos, uno detrás de otro: caminar, peregrinar. Por su naturaleza misma, la escritura va siempre más allá de ella misma; lo que buscamos no está en la escritura, excepto como señal o indicación: la escritura se anula y nos dice que aquello que buscamos está (es) allá (OC6: 56).

En un viaje posterior a la India, el poeta cuenta cómo un "caminar" se transforma en un "peregrinar" y se resuelve en iluminación. En una suerte de acrópolis, frente al rostro borroso de Buda esculpido en la piedra, el yo entra en éxtasis. "La cara y el viento" (Árbol adentro, OC12: 143) relata ese face à face con el Misterio:

Bajo un sol inflexible

llanos ocres, colinas leonadas.

Trepé por un breńal una cuesta de cabras

hacia un lugar de escombros:

pilastras desgajadas, dioses decapitados.

A veces, centelleos subrepticios: 
una culebra, alguna lagartija.

Agazapados en las piedras,

color de tinta ponzoñosa, pueblos de bichos quebradizos.

Un patio circular, un muro hendido.

Agarrada a la tierra — nudo ciego,

árbol todo raíces - la higuera religiosa.

Lluvia de luz. Un bulto gris: el Buda.

Una masa borrosa sus facciones, por las escarpaduras de su cara subían y bajaban las hormigas.

Intacta todavía, todavía sonrisa, la sonrisa:

golfo de claridad pacífica.

$Y$ fui por un instante diáfano

viento que se detiene,

gira sobre sí mismo y se disipa.

Este poema magistral dice a la vez la asunción del yo hacia lo Otro, y la disipación del yo y del poema en un "silencio cifrado". El "golfo de claridad pacífica" dibuja un ámbito sagrado al cual se accede después de un impulso inicial (“Trepé”) y de una serie de mediaciones que permiten la epifanía: "Lluvia de luz". Este poema hace lo que cuenta: al relatar una iniciación, hace al lector partícipe de aquel encuentro con el Ser.

\section{"Es música el silencio"}

"Respuesta y reconciliación" (1996), último poema de Paz publicado en vida del autor, evoca una experiencia parecida (OC12: 227): 
Por un instante, a veces, vemos

—no con los ojos: con el pensamiento-

al tiempo reposar en una pausa.

El mundo se entreabre y vislumbramos

el reino inmaculado,

las formas puras, las presencias

inmóviles flotando

sobre la hora, río detenido: [...]

Estos versos dicen nosotros, como para insistir en el carácter universal de la experiencia. Pero en los últimos versos del poema, el yo retoma la palabra y se asocia al nosotros. El poeta se asume como tal y vuelve a mencionar, por última vez, "el silencio" -su última palabra, por así decirlo, en un último oxímoron (OC12: 228)-:

Y mientras digo lo que digo

caen vertiginosos, sin descanso,

el tiempo y el espacio. Caen en ellos mismos.

El hombre y la galaxia regresan al silencio.

¿Importa? Sí — pero no importa:

sabemos ya que es música el silencio

y somos un acorde del concierto. 


\section{Bibliografía}

Dictionnaire de la sagesse orientale. Bouddhisme. Hindonisme. Taö̈sme. Zen, 1989 [1986], Robert Laffont, "Bouquins", París.

Esteban, Claude, 1987, Critique de la raison poétique, Flammarion, "Critiques", París.

Giraud, Paul-Henri, 2014, Octavio Paz: Hacia la transparencia, David Medina Portillo (trad.), El Colegio de México, Centro de Estudios Lingüísticos y Literarios, México.

Martín Velasco, Juan, 1993, Introducción a la fenomenología de la religión [1973], Cristiandad, Madrid.

Otto, Rudolf, 1980, Lo Santo. Lo racional y lo irracional en la idea de Dios [1925], Fernando Vela (trad.), Alianza Editorial, Madrid.

Paz, Octavio, 1994, La casa de la presencia: Poesia e historia, en Obras completas I, Octavio Paz (ed.), Fondo de Cultura Económica, México.

, 1995, Blanco / Archivo Blanco, 2 vols., Enrico Mario Santí (ed.), El Colegio Nacional / Ediciones del Equilibrista, México.

, 1994a, Los privilegios de la vista I: Arte moderno universal, en Obras completas VI, Octavio Paz (ed.), Fondo de Cultura Económica, México.

, 1996, Ideas y costumbres II: Usos y simbolos, en Obras completas X, Octavio Paz (ed.), Fondo de Cultura Económica, México.

, 1997, Obra poética I, en Obras completas XI, Octavio Paz (ed.), Fondo de Cultura Económica, México.

, 2003, Obra poética II, en Obras completas XII, Octavio Paz (ed.), Fondo de Cultura Económica, México. 
Stanton, Anthony, 1998, "Octavio Paz, Alfonso Reyes y el análisis del fenómeno poético" [1993], en Inventores de tradición, El Colegio de México / Fondo de Cultura Económica, México, pp. 205-220.

Suzuki, Daisetsu Teitaro, 1950, Manual of Zen Buddhism: From the Chinese Zen Masters, Londres.

Weinberger, Eliot, 1990, "Un cosmopolita en Asia”, en Octavio Paz. Los privilegios de la vista (catálogo de exposición), Centro Cultural Arte Contemporáneo, México, pp. 99-115.

, 1995, "Paz en la India", en Octavio Paz, Blanco / Archivo Blanco, 2 vols., Enrico Mario Santí (ed.), El Colegio Nacional / Ediciones del Equilibrista, México, pp. 189-202. 